\title{
Assessment of $\mathrm{CD56}^{+} \mathrm{CD69}^{+}$Natural Killer Cells in the Peripheral Blood of Women with Repeated Implantation Failure (RIF) undergoing an Intra Cytoplasmic Sperm Injection (ICSI) Cycle Yahia Abd El-Salam Wafa ${ }^{1}$, Salah El-Beltagy ${ }^{2}$, Osama Mohammed Deif', Mohammed Moustafa Abd El Hameed ${ }^{1}$
}

Departments of ${ }^{1}$ Obstetrics and Gynecology and ${ }^{2}$ Clinical Pathology Faculty of Medicine, Al-Azhar University

*Correspondence author: Mohammed Moustafa Abd El Hameed, Mobile: (+20) 01222546572 , E-mail: Medocology@ hotmail.com

\begin{abstract}
Background: infertility is an increasing medical and social problem. Delayed childbearing exposes couples to increased risk of causes of infertility including endometriosis, pelvic infection, and poor egg and sperm quality. Many infertile couples turn to in-vitro fertilization (IVF).

Objective: to analyze and compare between the peripheral blood NK cells $\left(\mathrm{CD}^{+} 6^{+} \mathrm{CD} 69^{+}\right)$in women with repeated ICSI failure.

Patients and Methods: the current study is a case control study. One hundred women were included and divided into two groups: The study group included 50 women with history of unexplained infertility and repeated implantation failure in their ICSI attempts and a control group which included 50 normal, non-pregnant and fertile women.

Results: the current study revealed that there was a highly statistically significant difference between control and case groups regarding CD3- CD56 $6^{\text {+dim }} \mathrm{NK}$ percentage with a p-value $<0.0001$. The current study revealed that there was a statistically significant difference between control and case groups regarding $\mathrm{CD} 3^{-} \mathrm{CD}^{- \text {+dim }} \mathrm{CD}^{-9^{+}} \mathrm{NK}$ cells percentages with a p-value 0.001 .

Conclusion: there was a highly statistically significant difference between control and case groups regarding CD3CD56 $6^{\text {+dim }}$ NK percentage. Also the study showed that total CD56 $6^{\text {+dim }} \mathrm{NK}$ had a very good predictive value as it had a sensitivity of $80.0 \%$, a specificity of $66.7 \%$, a PPV of $73.3 \%$ and a NPV of $78.8 \%$.
\end{abstract}

Keywords: CD56+ CD69+, Natural Killer Cells, IVF, RIF, ICSI

\section{INTRODUCTION}

There is still no formal consensus definition for repeated IVF failure (RIF), although suggestions included the failure of at least three cycles of IVF or two cycles of IVF plus two cycles using frozen embryos ${ }^{(\mathbf{1})}$.

Assumed etiologies for RIF may be attributed to many factors. These can be grouped into four categories: decreased endometrial receptivity, embryonic defects, operators' skills and factors with combined effect. Decreased endometrial receptivity is due to: uterine cavity abnormalities, thin endometrium, altered expression of adhesive molecules, immunological factors, and thrombophilia ${ }^{(2)}$.

Natural killer (NK) cells are bone marrowderived lymphocytes that function in the destruction of foreign, infected, or malignant cells and in the promotion of immune responses. A diverse repertoire of cell surface receptors control their activation, killing, cytokine production, and proliferation ${ }^{(3)}$.

NK cell function is tightly regulated by balancing between activating and inhibitory receptors. This balance is critical in preventing maternal rejection of the fetus and it is thought to be impaired in recurrent spontaneous abortions (RSA) and infertility ${ }^{(4)}$.

$\mathrm{CD}$ antigens are proteins, glycoproteins, and glycolipids serve as surface receptors and ligands, that regulate cell signaling, cell adhesion and adaptive immunity. CD molecules are commonly utilized in cell sorting techniques and cell populations are usually defined as either positive or negative; they control inhibition and activation; proliferation and effector functions (cytotoxicity and cytokine production) ${ }^{(5)}$.
$\mathrm{CD} 16$ is a low-affinity receptor for $\mathrm{IgG}$ complexes (FcrRIII) and is expressed on the majority of NK cells as well as on neutrophils, a small $\mathrm{T}$ cell population, and some activated macrophages. CD16 is the receptor responsible for NK-mediated antibodydependent cellular cytotoxicity ${ }^{(6)}$.

CD56 is an isoform of the neural cell adhesion molecule (NCAM), expressed on essentially all NK cells, a small population of cytotoxic $\mathrm{T}$ lymphocytes, and some neural-derived tissues. Based on the intensity of CD56 expression, NK cells can be divided in two populations. CD56 $6^{\mathrm{dim}}$ cells are more cytotoxic, whereas the CD56 ${ }^{\text {bright }}$ subset is the main source of NK cellderived immunoregulatory cytokines ${ }^{(7)}$.

CD69 belongs to the C-lectin type superfamily. It is a functional triggering molecule on activated NK cells and is one of the earliest cell surface activation markers. Besides mediating NK cell cytotoxicity, it also mediates other NK cell functions such as proliferation, tumour necrosis factor (TNF-a) production and expression of other activation antigens ${ }^{(8)}$.

In peripheral blood, CD56 $\mathrm{dim} / \mathrm{CD} 16^{+} \mathrm{NK}$ cells predominate in numbers and are mostly cytotoxic against specific targets and these cells have direct contact with chorionic villi at the intervillous space, whereas uterine natural killer (uNK) cells are predominantly a $\mathrm{CD} 56^{\text {bright }} / \mathrm{CD} 16^{+}$represent and are mostly cytokine producers ${ }^{(9)}$.

In non-pregnant endometrium, there is a significant increase in the numbers of uterine natural killer (uNK) cells from the mid secretory phase onward, where they are found close to stromal cells and around 
glands and blood vessels, and during human pregnancy, they are found in close proximity to the implantation site, in close contact with the infiltrating extravillous trophoblast. Uterine NK cells are closely associated with placental trophoblast cells and can regulate trophoblast invasion into the deciduas and regulation of the maternal immune response to the fetal allograft. They may also contribute in the control of local infections as well as in the process of angiogenesis through cytokine secretion $^{(\mathbf{1 0 )}}$.

In peripheral blood, the main population of NK cells $(90 \%)$ is CD56 $6^{\mathrm{dim}}$ cells. They are potent mediators of natural cytotoxicity and more cytotoxic than other NK subsets. These cells have direct contact with chorionic villi at the intervillous space and the manner the developing fetus evades NK cytotoxicity (NKc) from these cells may determine the pregnancy outcome ${ }^{(11)}$.

Rai et al. ${ }^{(12)}$ reported that an increase in the absolute count of activated NK cells $\left(\mathrm{CD} 56^{\mathrm{dim}}, \mathrm{CD} 16^{+}\right.$, $\mathrm{CD}^{+} 9^{+}$) is associated with a reduced implantation rate amongst women undergoing IVF. By inference it is suggested that (i) this is a useful test for women undergoing IVF, and (ii) therapeutic intervention of some sort to decrease peripheral blood NK cell activation will be of benefit to those women with an increased number of activated NK cells.

\section{AIM OF THE WORK}

To analyze and compare between the peripheral blood $\mathrm{NK}$ cells $\left(\mathrm{CD}^{+} 6^{+} \mathrm{CD} 69^{+}\right)$in women with repeated ICSI failure.

\section{SUBJECTS AND METHODS Study Design:}

This is a case control study that was conducted through the period from February 2017 to February 2019. One hundred women was included and divided into two groups:

Group 1 (study group): included 50 women with a history of repeated ICSI failures.

Group 2 (control group): included 50 normal, nonpregnant, and fertile controls.

\section{Study Setting:}

- IVF center of AL-Hussien Hospital, Al-Azhar University, Cairo Egypt.

- IVF center of Ahmed Maher Teaching Hospital, Cairo Egypt.

- IVF private centers.

\section{ETHICAL CONSIDERATION:}

- Patient information and informed consent:

Before being admitted to clinical study, the patient had to consent to participate after the nature, scope and possible consequences of the study were explained in an understandable form by the researcher himself.

\section{- Confidentiality:}

Only the patients' initials were recorded and if the patient's name appeared on any other documents it was kept in privacy by the researcher.

- Institutional review board (IRB) approval:
The clinical research study was conducted in accordance with the current IRB-approved clinical protocol; Internal Conference on Harmonisation and Good Clinical Practice (IHC GCP) Guidelines and relevant politics, requirements and regulations of Obstetrics and Gynecology Department, Faculty of Medicine, AL Azhar University.

\section{Written informed consent:}

An approval of the study was obtained from AlAzhar University academic and ethical committee. Every patient signed an informed written consent for acceptance of the operation.

\section{Methods:}

\section{Full history, examination and investigations:}

All women participating were subjected to the following:

1- Careful history was taken regarding personal, menstrual, obstetric, medical and surgical data.

2- Complete physical examination was done to exclude any disorders that may interfere with the results included: abdominal examination and pelvic examination.

3- Investigation included:

a) Transvaginal ultrasound to exclude any uterine abnormalities as (polycystic ovarian syndrome, uterine fibroids, uterine septum, uterine polyps).

b) Hormonal profile ( $\mathrm{FSH}, \mathrm{LH}$ prolactin and $\mathrm{E}_{2}$ ).

c) Fasting and postprandial blood sugar.

d) Thyroid function test.

e) Hysterosalpingography.

\section{Controlled ovarian hyperstimulation-embryo transfer} (COH-ET) using the standard long protocol of induction:

a- Ovarian hyperstimulation protocol was held according to a long GnRH agonist protocol starting from mid-luteal phase by daily subcutaneous injection of triptorelin acetate (Decapeptyl $0.1 \mathrm{mg}$, Ferring Pharmaceutical, Kiel, Germany).

b- After ensuring downregulation by serum E2 $<50$ $\mathrm{pg} / \mathrm{ml}$, ovarian hyperstimulation was started on day 3 of next cycle by daily injection of HMG (Merional 75 IU/amp "IBSA", Switzerland). The starting dose was $225 \mathrm{IU} /$ day (3 ampoules), folliculometry was done on day 8 and the doses of gonadotropins were continuously adapted according to folliculometry and ovarian response.

c- According to ovarian response, day after day transvaginal ultrasound was performed till the largest follicle reached a diameter of $(18-22 \mathrm{~mm})$ using (transvaginal probe of $7.5 \mathrm{MHz}$ of Mindray China DP 8800 ultrasound machine) in ART unit. The maximum duration of HMG was not allowed to exceed day 16. The size and number of the growing follicles were accurately registered in the patients' sheets.

d- HCG (Choriomon 10000 IU/amp. "IBSA, Switzerland") was administered by deep intramuscular injection. 
e- 36 hours after HCG injection, ovum pickup was carried out under general anesthesia. The transducer was connected to the ultrasound system. The direction of the guide beam was checked. The puncturing needle (single way catheter Cook medical needle "Bloomington, USA") was connected to an aspiration apparatus (pressure adjusted at $100-150 \mathrm{mmHg}$ ) attached by fixation ring to the front and rear ends of the vaginal transducer, thereby defining the direction of puncture corresponding to the guide beam on the ultrasound image. The uterus, both ovaries and iliac vessels were identified by the visualization in both planes. The distance between the upper pole of the vagina and the ovary were closely evaluated (care was taken to avoid intestinal or vascular interposition).

f- The aspirate was checked using microscopy.

g- Oocyte for ICSI was subjected to enzymatic decoronisation by hyaluronidase (Fertipro NV, Beernem, Belgium). Each sperm, selected according to their mobility and morphology, was transferred to a drop of polyvinylpyrrolidone (PVP, Irvine Scientific, USA). The oocyte was microinjected using micromanipulators mounted on an inverted microscope (Olympus IX71). The oocyte was then cultured in an incubator (Galaxy, R170-200P, UK) containing culture medium (Global LOT, Life Global, USA). The inseminated oocyte was evaluated approximately 18 hours later for pronuclear formation, and the resulting embryos were placed in growth medium and the best three embryos were selected for transfer.

h- Abdominal ultrasound guided mid-cavity embryo transfer (Shenzen Mindray Bio-Medical Electronic, model DP 8800 plus) using soft catheter (Labotect catheter, Germany) was performed on day 3 or 5 after oocyte retrieval, with three embryos per transfer.

i- Progesterone supplement for luteal support (Cyclogest; Shire Pharmaceuticals Ltd, UK), $400 \mathrm{mg}$ once a day per vaginum or per rectum, was commenced 1 day before embryo transfer and continued until a pregnancy test was performed 16 days after oocyte retrieval.

\section{Flow Cytometric Analyses:}

Blood samples were obtained during mid luteal phase of the menstrual cycle, which was known by selfreporting regarding to control group and by operator reporting regarding to cases group.

The flow cytometric analysis was performed at Flow Cytometry Laboratory. Ten $\mathrm{ml}$ of peripheral blood samples were collected in heparinized tubes after informed oral consent. One hundred $\mu 1$ of each specimen were pipetted in tubes and labeled with patient's name and $10 \mathrm{ml}$ of the following monoclonal antibodies were added to the specimens:

- Anti-CD3 R phycoerythrin-cyanin 5 (PC5) conjugated (mouse monoclonal IgG), (supplied by Immunetech, Beckman coulter company, ref A07749, France).

- Anti-CD56 R phycoerythrin (PE) conjugated (mouse monoclonal IgG) (supplied by Immunotech, Beckman coulter company, ref A07788, France).
Anti-CD69 fluorescein conjugated (mouse monoclonal IgG2A), (supplied by $\mathrm{R} \& \mathrm{D}$ systems, FAB23591F, Egypt). Negative isotype matched controls for the 3 markers (CD3, CD56 and CD69) were included with each sample (IgG1-PC5 isotype control supplied by Immunotech, Beckman coulter company, ref A07798, France, IgG1-PE isotype control supplied by Immunotech, Beckman coulter company, ref A07796, France and IgG-fluorescein isotype control supplied by R\&D systems, IC003F, Egypt respectively).

Reagents were provided in phosphate buffer saline (PBS: $0.01 \mathrm{M}$ sodium phosphate, $0.145 \mathrm{M}$ sodium chloride. $\mathrm{pH}$ 7.2), with $0.1 \%$ sodium azide as a preservative and $2 \mathrm{mg} / \mathrm{ml}$ bovine serum albumin.

Specimens were incubated in the dark at room temperature for $15 \mathrm{~min}$, then $1 \mathrm{ml}$ of lysing solution was added and mixed well, to be incubated again in the dark at room temperature for $10 \mathrm{~min}$, centrifuged for $5 \mathrm{~min}$ at $2000 \mathrm{rpm}$ and the supernatant was discarded. Cells were then washed with PBS and the cell pellet was resuspended in 200-500 ml PBS. Flow cytometric analysis was performed on the Becton Deckinson FACS caliber flow cytometer using Cell Quest Software (Becton Deckinson). Cells negatively stained for CD3, positively for CD56 were selected and CD69 expression was analyzed.

The results were expressed as the percentage of the positive cells relative to the isotype control (\%) and expression or mean fluorescence intensity (MFI) which is defined as the ratio between the MFI of the cells incubated with the tested monoclonal antibodies and the MFI of the cells incubated with isotype matched control.

\section{Statistical analysis}

Recorded data were analyzed using the statistical package for social sciences, version 20.0 (SPSS Inc., Chicago, Illinois, USA). Quantitative data were expressed as mean \pm standard deviation (SD). Qualitative data were expressed as frequency and percentage. Independentsamples t-test of significance was used when comparing between two means. P-value $<0.05$ was considered significant.

\section{RESULTS}

Table (1): Patient characteristics regarding age and menstrual cycle

\begin{tabular}{|l|l|c|c|c|c||}
\hline \multirow{2}{*}{ Variable } & \multicolumn{2}{|c|}{ Cases (n=50) } & \multicolumn{2}{|c|}{$\begin{array}{c}\text { Controls } \\
(\mathbf{n = 5 0})\end{array}$} & \multicolumn{1}{c|}{$\begin{array}{c}\text { p- } \\
\text { value }\end{array}$} \\
\cline { 2 - 5 } & Mean & SD & Mean & SD & \\
\hline Age (years) & 28.94 & $(7.34)$ & 31.02 & $(6.16)$ & 0.128 \\
\hline $\begin{array}{l}\text { Menstrual } \\
\text { cycle } \\
\text { Length } \\
\text { (days) }\end{array}$ & 28.5 & $(1.2)$ & 28.3 & $(1.1)$ & 0.387 \\
\hline $\begin{array}{l}\text { Menses } \\
\text { duration } \\
\text { (days) }\end{array}$ & 4.2 & $(0.8)$ & 4.3 & $(0.9)$ & 0.558 \\
\hline
\end{tabular}

Table (1) show the characteristics of controls and cases regarding age and menstrual cycle. 
Table (2): History of previous assisted reproduction in cases

\begin{tabular}{|l|c|}
\hline \multicolumn{1}{|c|}{ Variable } & Metric \\
\hline Type of infertility, $1^{\text {ry }} 2^{\text {ry }}$ & $43 / 7$ \\
\hline Duration of infertility, years & $7.76(2.22)$ \\
\hline FSH level, mIU/l & $7.06(1.58)$ \\
\hline LH level, mIU/l & $3.53(1.18)$ \\
\hline Prolactin level, ng/ml & $9.34(3.57)$ \\
\hline TSH level, mIU/ml & $2.03(1.17)$ \\
\hline Number of previous attempts of induction of ovulation & $3.0(0-9)$ \\
\hline Number of previous failed ICSI attempts & \\
\hline Three attempts & $45(90.0 \%)$ \\
\hline four attempts & $5(5.0 \%)$ \\
\hline Number of transferred embryos in previous failed ICSI attempts & $6.0(5-10)$ \\
\hline
\end{tabular}

Data are presented as ratio, mean (SD), median (interquartile range), or number (\%).

Table (2) describe the history of previous assisted reproduction in cases patients, the cases group were divided in to two categories, women with $1^{\text {ry }}$ infertility (43 cases) and $2^{\text {ry }}$ infertility ( 7 cases). It also shows the duration of infertility among patients in the cases group with a mean 7.76 years and SD 2.22.

Table (3): Comparison between cases and controls as regard total lymphocyte percentage (\%), CD3- CD56 $^{+d i m}$ NK \% and CD3- CD69 NK \%

\begin{tabular}{|c|c|c|c|}
\hline Variable & Cases $(\mathbf{n}=\mathbf{5 0})$ & Controls $(\mathbf{n}=\mathbf{5 0})$ & p-value \\
\hline Total lymphocyte \% & $33.8(8.21)$ & $33.4(8.81)$ & 0.815 \\
\hline CD3 ${ }^{-}$CD56 $6^{+\operatorname{dim}}$ NK \% & $14.26(6.25)$ & $7.92(5.82)$ & $\mathbf{0 . 0 0 0 1}$ \\
\hline CD3 ${ }^{-}$CD 69 NK \% & $14.52(8.78)$ & $12.8(7.12)$ & $\mathbf{0 . 4 9 0}$ \\
\hline
\end{tabular}

Table (3) demonstrate that there was no statistically significant difference in total lymphocytic percentage and CD3 ${ }^{-}$CD 69 NK\% among both groups.

Table (4): Comparison between cases and controls as regard $\mathrm{CD3}^{-} \mathrm{CD56}^{+\mathrm{dim}} \mathrm{CD69}^{-\mathrm{NK} \%}$ expression

\begin{tabular}{|c|c|c|c|}
\hline Variable & Cases $(\mathbf{n}=\mathbf{5 0})$ & Controls $(\mathbf{n}=\mathbf{5 0})$ & p-value \\
\hline \hline $\mathrm{CD}^{-} \mathrm{CD}^{+} 6^{\text {+dim }} \mathrm{CD}^{+}{ }^{+} \mathrm{NK} \%$ & $3.19(1.62)$ & $1.98(0.97)$ & $\mathbf{0 . 0 0 1}$ \\
\hline
\end{tabular}

Table (4) show that cases had higher percentage of CD3 ${ }^{-}{ }^{2} 56^{+\operatorname{dim}} \mathrm{CD} 69^{+} \mathrm{NK}$ cells which is highly statistically significant $(\mathrm{p}<0.01)$.

Table (5): Comparison between cases and controls as regard total CD 56 NK and total 69 NK\%

\begin{tabular}{|l|c|c|c|c|}
\hline & Case & Control & t/ Mann Whitney & P \\
\hline Total CD 56 & $17.46(6.11)$ & $9.84(3.7)$ & 5.937 & $<0.01 * *$ \\
\hline Total CD 69 & $17.72(8.7)$ & $14.72(6.3)$ & 1.165 & 0.247 \\
\hline
\end{tabular}

Table (5) shows that cases were significantly higher as regard total CD 56.

Flow cytometric analyses results:

No specific statistical comparison was made regarding the expression of CD56 as the included samples in this study were of the dim type expression.
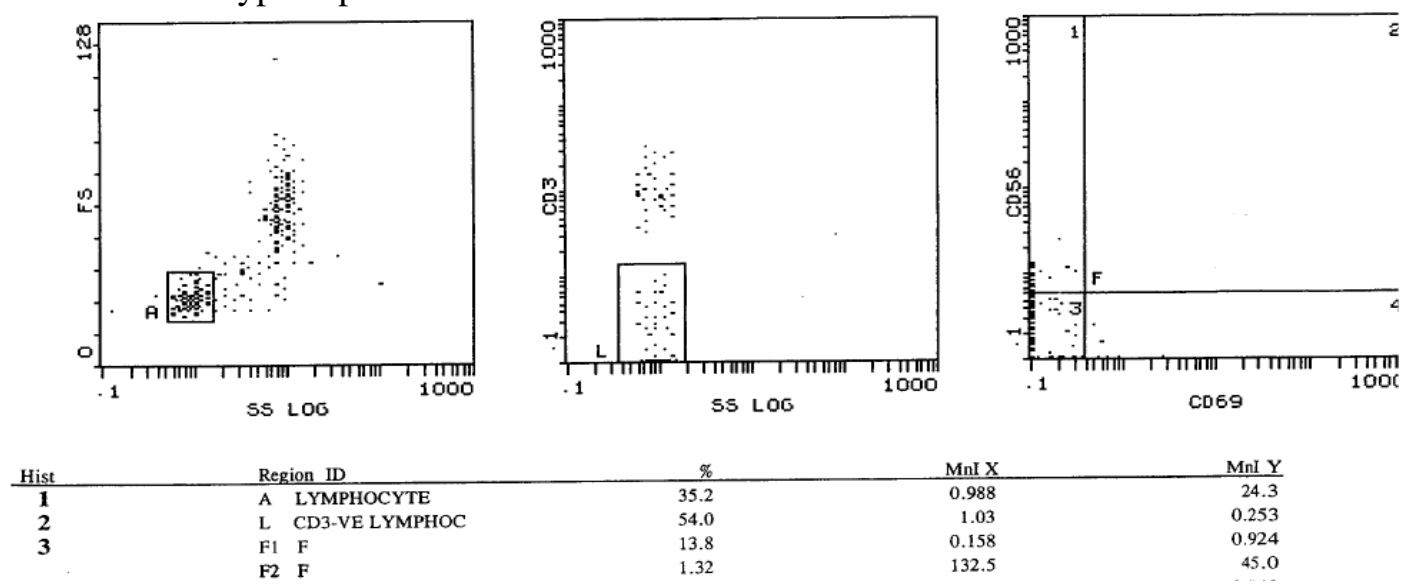

Figure (1): Flow cytometry report of a subject included in the study showing forward scattering (FSC) versus side scattering (SSC) with dot blot of: (A) gated lymphocyte population, (L) gated CD3- lymphocyte population (F1) $\mathrm{CD}^{+} 6^{\text {+dim }}$ and (F2) $\mathrm{CD}^{+ \text {+dim }} \mathrm{CD}^{+} 9^{+}$. 

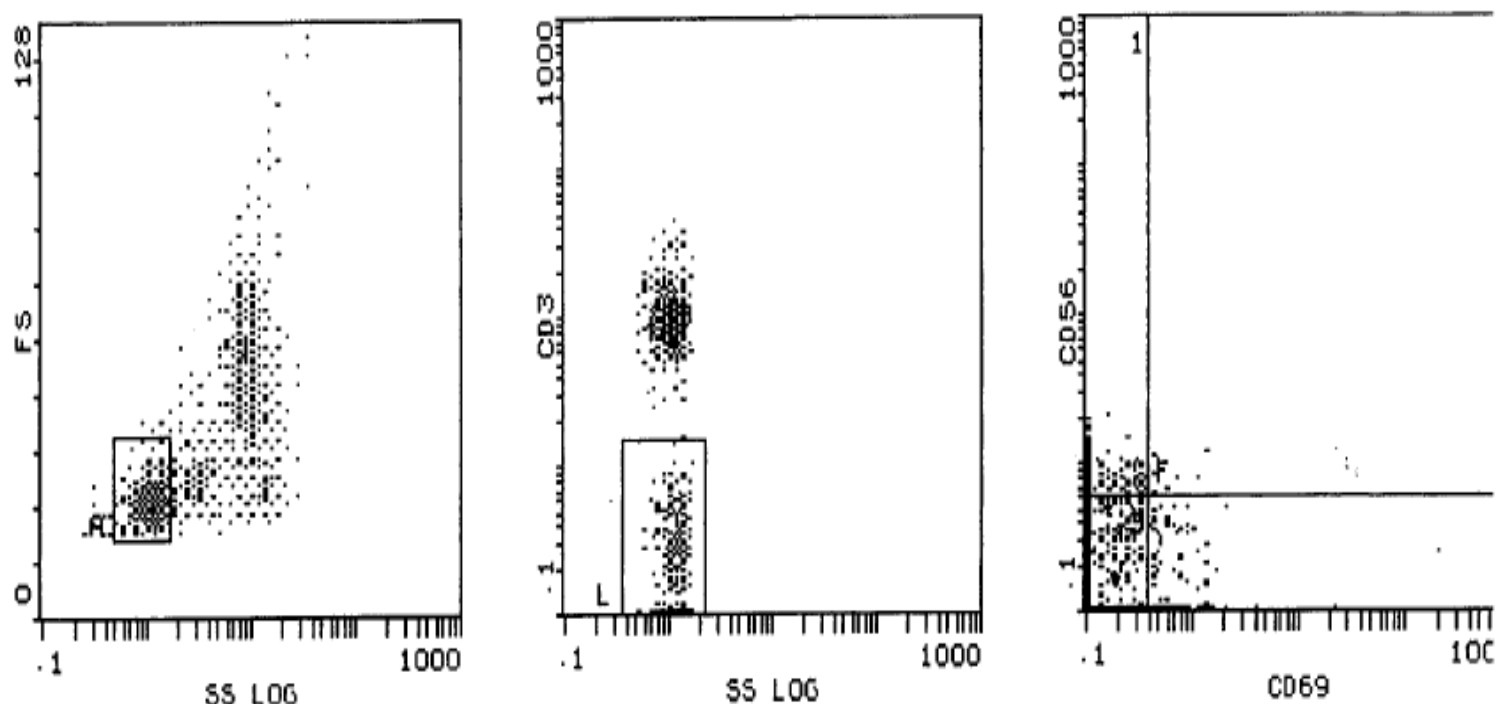

\begin{tabular}{clrrr} 
Hist & Region ID & $\%$ & MnI X & MnI Y \\
\hline $\mathbf{1}$ & A LYMPHOCYTE & 36.7 & 1.14 & 24.8 \\
$\mathbf{2}$ & L CD3-VE LYMPHOC & 49.9 & 1.21 & 0.259 \\
$\mathbf{3}$ & F1 F & 15.3 & 0.153 & 0.915 \\
& F2 F & 1.60 & 47.9 & 14.8
\end{tabular}

Figure (2): Flow cytometry report of a subject included in the study showing: FSC versus SSC with dot blots of: (A) gated lymphocyte population, (L) gated $\mathrm{CD}^{-}$lymphocyte population (F1) $\mathrm{CD} 56^{\text {+dim }}$ and (F2) $\mathrm{CD} 56^{+\mathrm{dim}} \mathrm{CD} 9^{+}$.

Table (6): Correlation between various biomarkers (total $\mathrm{CD}^{+ \text {dim }} \%$ and total $\mathrm{CD} 69^{+} \%$ ) and age, FSH, $\mathrm{LH}, \mathrm{E} 2$, prolactin, TSH and number of previous attempts of ovulation induction, of failed attempts of ICSI and of embryos transferred in previous failed ICSI attempts

\begin{tabular}{|c|c|c|c|c|}
\hline \multirow{3}{*}{ Age } & & CD56_positive & CD69_positive & CD56_CD69 \\
\hline & $\mathrm{r}$ & $0.297^{* *}$ & $0.198^{*}$ & $0.273^{* *}$ \\
\hline & $\mathrm{P}$ & 0.003 & 0.049 & 0.006 \\
\hline \multirow[t]{2}{*}{ FSH } & $\mathrm{r}$ & 0.144 & $-0.165-$ & $-0.149-$ \\
\hline & $\mathrm{P}$ & 0.319 & 0.251 & 0.300 \\
\hline \multirow[t]{2}{*}{ LH } & $\mathrm{r}$ & 0.278 & $-0.091-$ & $-0.063-$ \\
\hline & $\mathrm{P}$ & 0.050 & 0.528 & 0.665 \\
\hline \multirow[t]{2}{*}{ E2 } & $\mathrm{r}$ & $-0.934-$ & 0.478 & $-0.128-$ \\
\hline & $\mathrm{P}$ & 0.066 & 0.522 & 0.872 \\
\hline \multirow[t]{2}{*}{ Prolactin } & $\mathrm{r}$ & 0.166 & 0.182 & 0.179 \\
\hline & $\mathrm{P}$ & 0.248 & 0.205 & 0.213 \\
\hline \multirow[t]{2}{*}{ TSH } & $\mathrm{r}$ & $-0.044-$ & 0.040 & 0.000 \\
\hline & $\mathrm{P}$ & 0.764 & 0.781 & 0.997 \\
\hline \multirow{2}{*}{$\begin{array}{l}\text { No of previous attempts of ovulation } \\
\text { induction }\end{array}$} & $\mathrm{r}$ & 0.076 & $-0.103-$ & $0.302^{*}$ \\
\hline & $\mathrm{P}$ & 0.601 & 0.477 & 0.033 \\
\hline \multirow[t]{2}{*}{ No of failed attempts of ICSI } & $\mathrm{r}$ & 0.240 & 0.007 & 0.069 \\
\hline & $\mathrm{P}$ & 0.093 & 0.960 & 0.636 \\
\hline \multirow{2}{*}{$\begin{array}{l}\text { No of embryos transferred in previous failed } \\
\text { ICSI attempts }\end{array}$} & $\mathrm{r}$ & 0.164 & 0.070 & $-0.054-$ \\
\hline & $\mathrm{P}$ & 0.255 & 0.627 & 0.710 \\
\hline
\end{tabular}

Table (6) shows that no statistically significant correlation was found regarding total CD56 ${ }^{+\mathrm{dim}} \%$ and total $\mathrm{CD} 69^{+} \%$ and age 


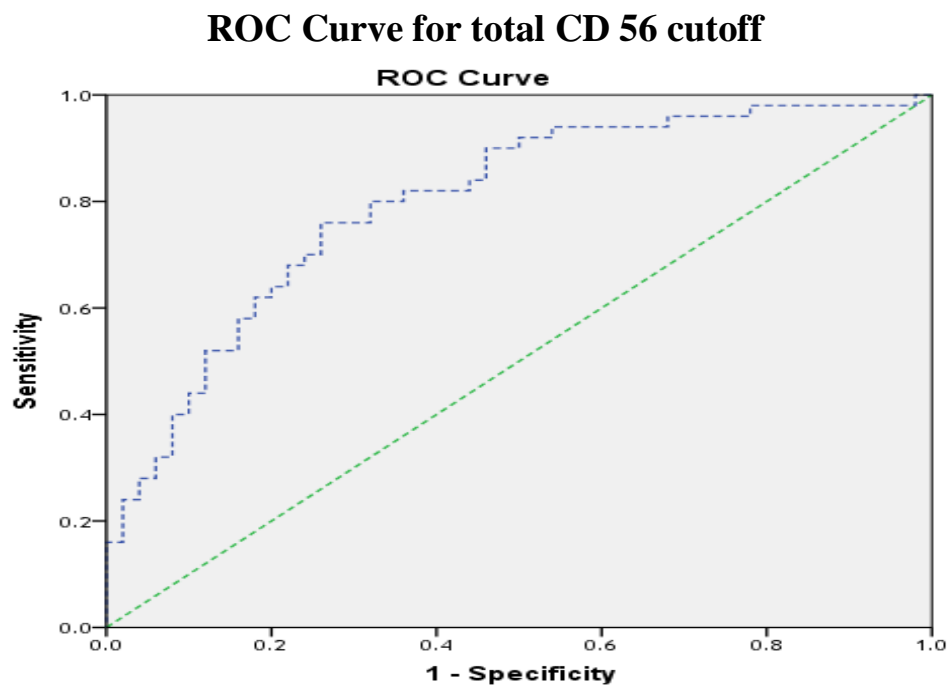

\begin{tabular}{|c|c|c|c|c|c|c|c|c|c|}
\hline \multirow[t]{2}{*}{ Area } & \multirow[t]{2}{*}{ Cutoff } & \multirow[t]{2}{*}{$\mathbf{P}$} & \multicolumn{2}{|c|}{$\begin{array}{r}\text { 95\% Confidence } \\
\text { Interval }\end{array}$} & \multirow[t]{2}{*}{ Sensitivity } & \multirow[t]{2}{*}{ Specificity } & \multirow[t]{2}{*}{$\begin{array}{r}+\mathrm{VE} \\
\text { predictive }\end{array}$} & \multirow[t]{2}{*}{$\begin{array}{r}-\mathrm{VE} \\
\text { predictive }\end{array}$} & \multirow[t]{2}{*}{ Accuracy } \\
\hline & & & $\begin{array}{l}\text { Lower } \\
\text { Bound }\end{array}$ & $\begin{array}{l}\text { Upper } \\
\text { Bound }\end{array}$ & & & & & \\
\hline 0.798 & $>13.9$ & $0.01 * *$ & 0.712 & 0.885 & $80.0 \%$ & $66.7 \%$ & $73.3 \%$ & $\mathbf{7 8 . 8 \%}$ & $\mathbf{7 5 . 0 \%}$ \\
\hline
\end{tabular}

Figure (3): Receiver-operating characteristic (ROC) curve for the value of CD56 ${ }^{+\mathrm{dim}} \mathrm{NK}$ in the prediction of repeated implantation failure (RIF). Dotted line represents reference line.

Figure (3) shows the result of receiver-operating characteristic (ROC) curve analysis for the value of CD56 $6^{\text {+dim }}$ NK in the prediction of repeated implantation failure (RIF).

CD56 $6^{\text {+dim }} \mathrm{NK}$ had a very good predictive value as evidenced by an area under the ROC curve (AUC) of 0.798 . The best cut-off value was a CD56 ${ }^{\text {dim }}$ NK percentage of $>13.9 \%$ (Youden index J, 0.43) (Figure 3).

\section{ROC Curve for CD56 and CD69 cutoff}

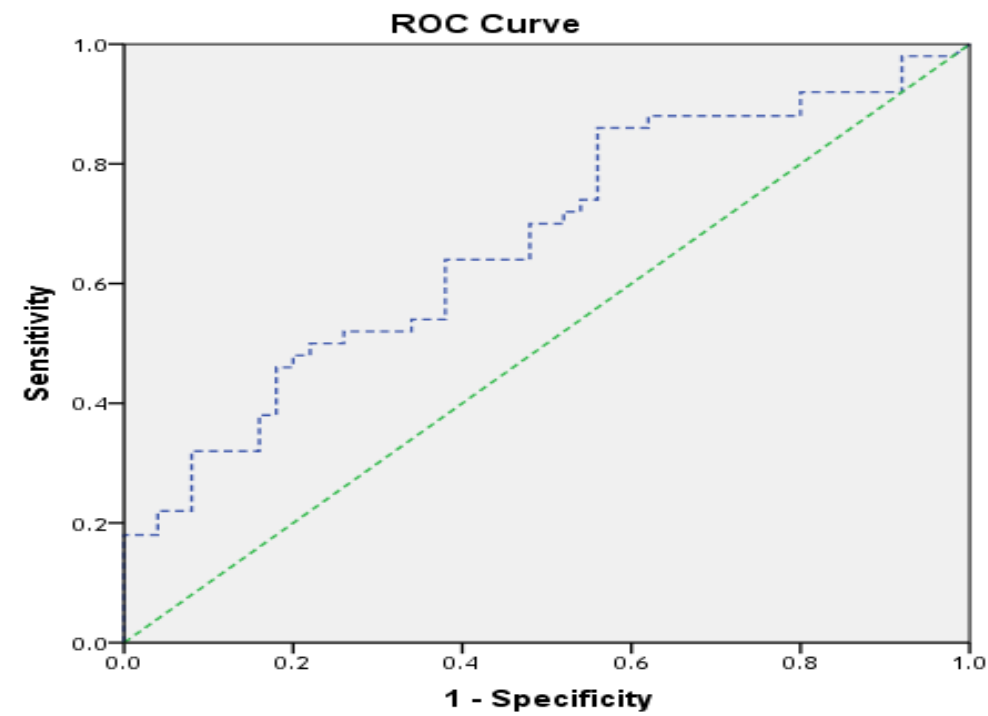

Diagonal segments are produced by ties.

\begin{tabular}{|c|c|c|c|c|c|c|c|c|c|}
\hline \multirow{2}{*}{ Area } & \multirow{2}{*}{ Cutoff } & \multirow{2}{*}{$\mathbf{P}$} & \multicolumn{2}{|c|}{$\begin{array}{c}\text { 95\% Confidence } \\
\text { Interval }\end{array}$} & \multirow{2}{*}{ Sensitivity } & \multirow{2}{*}{ Specificity } & \multirow{2}{*}{$\begin{array}{c}+\mathrm{VE} \\
\text { predictive }\end{array}$} & \multirow{2}{*}{$\begin{array}{c}-\mathrm{VE} \\
\text { predictive }\end{array}$} & \multirow{2}{*}{ Accuracy } \\
\hline & & & $\begin{array}{l}\text { Lower } \\
\text { Bound }\end{array}$ & $\begin{array}{l}\text { Upper } \\
\text { Bound }\end{array}$ & & & & & \\
\hline 0.711 & $>2.11$ & 0.003* & 0.566 & 0.877 & $67.7 \%$ & $63.3 \%$ & $60.0 \%$ & $63.3 \%$ & $62.2 \%$ \\
\hline
\end{tabular}

Figure (4): Receiver-operating characteristic (ROC) curve for the value of CD56 ${ }^{\text {+dim }}$ and CD69 ${ }^{+} \mathrm{NK}$ in the prediction of repeated implantation failure (RIF). Dotted line represents reference line.

Figure (4) shows the result of receiver-operating characteristic (ROC) curve analysis for the value of CD56 $6^{\text {+dim }}$ and $\mathrm{CD} 69^{+} \mathrm{NK}$ in the prediction of repeated implantation failure (RIF).

$\mathrm{CD}^{+\mathrm{dim}}$ and $\mathrm{CD} 69^{+} \mathrm{NK}$ had a very good predictive value as evidenced by an area under the ROC curve (AUC) of 0.711 . The best cut-off value was a CD56 $6^{+\mathrm{dim}}$ and CD69 $9^{+} \mathrm{NK}$ percentage of $>2.11 \%$ (Youden index J, 0.43) (Figure 4). 


\section{DISCUSSION}

In current study, there was no significant difference between cases and control regarding maternal age. In addition, menstrual cycle length showed no significant difference between cases and control groups, which indicates that the whole study population had regular cycles.

Regarding the infertile cases, average duration of infertility was $7.76 \pm 2.2$ years. There were 45 out of 50 cases $(90 \%)$ had history of 3 failed ICSI attempts whereas only 5 patients $(10 \%)$ had history of 4 failed ICSI attempts while five to ten embryos were transferred in all previous attempts. There is no correlation between number of previous failed IVF attempts, ovarian stimulation outcome or number of embryos transferred and CD56 ${ }^{\text {dim }}, \mathrm{CD} 56^{+\mathrm{dim}} \mathrm{CD} 69^{+} \mathrm{NK}$ cells. This could imply that ovarian hyperstimulation does not affect peripheral natural killer cells. This complies with Thum et al. ${ }^{(13)}$, who stated that there is no correlation between increased $\mathrm{CD} 56^{\text {+dim }}$, $\mathrm{CD} 16^{+} \mathrm{CD} 69^{+} \mathrm{NK}$ cells in the peripheral blood and these variables.

There was also no statistically significant differences between cases and control groups regarding total lymphocytic percentage.

In the current study we found that there was high statistically significant difference between cases and control groups regarding total peripheral $\mathrm{CD}^{-}$ CD56 ${ }^{\text {+dim }}$ NK Cells percentages; and this illustrates that the cases group had a larger percentage of cytotoxic peripheral NK cells than control.

In our study we reported that there was significant difference between women with RIF and normal fertile control regarding CD3- $\mathrm{CD} 56^{\text {+dim }} \mathrm{CD} 69^{+}$ NK cells percentages. It is also reported that the cases group had a very high cytotoxic state of NK cells than control group due to high expression of $\mathrm{CD} 69^{+}$marker on $\mathrm{CD} 56^{+\mathrm{dim}} \mathrm{NK}$ cells as $\mathrm{CD}^{+} 9^{+}$is an early activation marker for NK cells.

Our current study, CD56 ${ }^{+ \text {dim }}$ NK had a very good predictive value as evidenced by an area under the ROC curve (AUC) of 0.798 (95\% CI, 0.712 to 0.885 ; pvalue, <0.0001). This had a sensitivity of $80 \%$, a specificity of $66.7 \%$, a PPV of $73.3 \%$, and a NPV of $78.8 \%$.

On the other hand, the current study showed that, $\mathrm{CD}^{+ \text {+dim }} \mathrm{CD}^{-} 9^{+} \mathrm{NK}$ cells had a very good predictive value as evidenced by an AUC of 0.711 (95\% CI, 0.566 to 0.877 ; p-value 0.003). This had a sensitivity of $67.7 \%$, a specificity of $63.3 \%$, a PPV of $60.0 \%$, and a NPV of $63.3 \%$.

Our study results regarding the total lymphocytic count percentage agree with case-control study that was authorized by Viktor et al. ${ }^{(14)}$, the study was done on 41 patients with history of implantation failure and 38 patients with successful implantation in their ICSI cycle, they stated that there is no significant difference in total lymphocytic count between the 2 groups which were $\left(5.2 \pm 1.3\right.$ cells x $10^{9} \mathrm{~L} ; 1.7 \pm 0.4 \times$
$10^{9} \mathrm{~L} ; 3.1 \pm 1.1$ cells $10^{9} \mathrm{~L}$ ) in implantation failure group and $\left(5.2 \pm 1.1\right.$ cells $\times 10^{9} \mathrm{~L} ; 1.9 \pm 0.4$ cells $\times 10^{9} \mathrm{~L}$; $3.1 \pm 1.1$ cells $\times 10^{9} \mathrm{~L}$ ) in implantation success group.

Sacks et al. ${ }^{(15)}$, Beer et al. ${ }^{(16)}$, and Michou et al. (17) stated that women with RIF had altered peripheral blood NK cell percentage compared with normal fertile control group but they also reported that the test had a low sensitivity (11\%) as many women with RIF are likely to have multiple problems or may simply be unlucky with embryo genetic quality. The test is an ineffective tool to distinguish women who may develop RIF from a general population, but an effective test in differentiating subgroups within the RIF population.

Our results showed that there was significant difference between cases and control groups regarding CD56 $6^{\text {+dim }}$ NK cells reverse a higher cytotoxic state of peripheral blood in cases group than control, this is coincides with the study results of Mehri et al. ${ }^{(18)}$, who stated that $\mathrm{CD} 3{ }^{-\mathrm{CD} 56^{\text {+dim }}} \mathrm{NK}$ cells percentage in women with RIF was elevated compared to successful IVF group with mean (range) $(14.01(8.50-22.87) \%$ and $5.95(4.47-7.82) \%$ for each group respectively with $\mathrm{p}$ value $<0.001$ ), they also found statistically significant difference between normal fertile control and women with recurrent spontaneous abortions regarding CD3 CD56 $6^{\text {+dim }}$ NK cells percentage with mean (range) (5.98 $(2.42-8.69) \%$ and $13.10(9.24-24.24) \%$ for each group respectively with p-value $<0.001$ ).

In contrast, this finding disagrees with Thum et al. ${ }^{(13)}$ who reported no difference in CD56 $6^{\text {+dim }} \mathrm{NK}$ cell CD56 $6^{\text {+dim }}$ percentage between successful and unsuccessful ICSI patients with $(\mathrm{P}>0.05)$, this study was done on 75 patients of unsuccessful ICSI cycle and 51 patients of successful ICSI cycle. The mean \pm SD of CD56 $6^{\mathrm{dim}}$ NK cell percentage were $(9.7 \pm 2.1 \%$ and $10.9 \pm 2.3 \%$ for each group respectively). This disagreement with our results can be explained that the subjects included all women undergoing IVF rather than those with RIF as in our study.

On the other hand, Mehri et al. ${ }^{(18)}$ agree with our study results regarding the significant difference between cases and controls regarding $\mathrm{CD} 56^{+\mathrm{dim}} \mathrm{CD} 69^{+}$ NK cells percentage (P-value 0.003 ), they reported that percentage of $\mathrm{CD} 56^{+\mathrm{dim}} \mathrm{CD} 69^{+}$surface markers of $\mathrm{NK}$ cells was highly elevated in IVF failure group other than successful IVF group with mean (range) (1.68 (0.79$8.85) \%$ and $0.25(0.14-0.98) \%$ for each group respectively; $\mathrm{p}$-value $<0.001)$.

However, this results disagrees with Baczkowski and Kurzawa ${ }^{\left({ }^{(9)}\right)}$ who reported that there is no difference in $\mathrm{CD} 9^{+}$expression on peripheral blood lymphocyte subpopulations including $\mathrm{T}$ and $\mathrm{B}$ and NK cells among fertile control group and infertile women who achieved and those who did not achieve a pregnancy after intracytoplasmic sperm injection (ICSI). In this study, they used pregnant women within the control group instead of non-pregnant healthy women as control group. 


\section{CONCLUSION}

It should be concluded that; there was a highly statistically significant difference between control and case groups regarding CD3- CD56 ${ }^{\text {+dim }} \mathrm{NK}$ percentage. Also the study showed that total CD56 $6^{\text {+dim }} \mathrm{NK}$ had a very good predictive value as it had a sensitivity of $80.0 \%$, a specificity of $66.7 \%$, a PPV of $73.3 \%$ and a NPV of $78.8 \%$.

Our study also reported that there was a statistically significant difference between control and case groups regarding $\mathrm{CD} 3^{-} \mathrm{CD} 56^{\text {+dim }} \mathrm{CD} 69^{+} \mathrm{NK}$ cells percentages. And that $\mathrm{CD} 56^{\text {+dim }} \mathrm{CD} 69^{+} \mathrm{NK}$ cells had a very good predictive value as it had a sensitivity of $67.7 \%$, a specificity of $63.3 \%$, a PPV of $60 . \%$, and a NPV of $63.3 \%$.

\section{RECOMMENDATIONS}

- The results of this study need to be replicated on a larger scale to strengthen conclusions made. It would be beneficial to look at endometrium throughout the menstrual cycle, with the receptors used, to identify the pattern of behavior for these cells.

- It would be useful to study leukocyte trafficking markers, at various stages in the cycle.

- Future trials of immune therapy in women undergoing IVF should target those with high NK activity.

\section{REFERENCES}

1. Tuckerman E, Mariee N, Prakash A, Li TC, Laird S (2010): Uterine natural killer cells in peri-implantation endometrium from women with repeated implantation failure after IVF. J Reprod Immunol., 87:60-66.

2. Margalioth EJ, Ben-Chetrit A, Gal M and Eldar-Geva T (2006): Mini Review-Developments in Reproductive Medicine, Investigation and treatment of repeated implantation failure following IVF-ET, Human Reproduction, 21(12): 3036-3043.

3. Lanier LL (2005): NK cell recognition. Annu Rev Immunol., 23:225-274.

4. Nitrivals EI, Bowser CR, Kwak-Kim J, Beaman KD, Gilman-Sachs A (2005): Expression of killer immunoglobulin-like receptors on peripheral blood NK cell subsets of women with recurrent spontaneous abortions or implantation failures. Am J Reprod Immunol., 53:215-221.

5. Colucci F, Caligiuri MA, Di Santo JP (2003): What does it take to make a natural killer? Nat. Rev. Immunol., 3: 413-425.

6. Leibson PJ (1997): Signal transduction during naturalkiller-cell activation: inside the mind of a killer. Immunity, 6: 655-66.
7. Cooper MA, Fehniger TA, Turner SC et al. (2001): Human natural killer cells: a unique innate immunoregulatory role for the CD56 $6^{\text {bright }}$ subset. Blood, 97:31463151.

8. Pisegna S, Zingoni A, Pirozzi G, Cinque B, Cifone MG, Morrone S, Piccoli M, Frati L, Palmieri G and Santoni A (2002): Src-dependent Sky activation controls CD69mediated signaling and function on human NK cells. J Immunol., 169(1): 68-74.

9. Fauriat C, Long EO, Ljunggren HG, Bryceson YT (2010): Regulation of human NK-cell cytokine and chemokine production by target cell recognition. Blood, 115(11):2167-76.

10.Trundley A and Moffett A (2004): Human uterine leukocytes and pregnancy. Tissue Antigens, 63: 1-12.

11.Kwak-Kim J and Gilman-Sachs A (2008): Clinical implication of natural killer cells and reproduction. Am J Reprod Immunol., 59: 388-400.

12. Rai R, Sacks G, Trew G (2005): Natural killer cells and reproductive failure-theory, practice and prejudice. Human Reproduction, 20(5):1123-1126.

13. Thum M, Bhaskaran S, Bansal A, Shehata H, Ford BS, Abdalla H (2005): Simple enumerations of peripheral blood natural killer (CD56 + NK) cells, B cells and T cells have no predictive value in IVF treatment outcome. Hum Reprod., 20:1272-1276.

14. Viktor PC, Iryna OS, Boris VD, Anton AK, Yulia VM (2010): Elevated NK Cell Cytotoxicity, CD158a Expression in NK Cells and Activated T Lymphocytes in Peripheral Blood of Women with IVF Failures. American Journal of Reproductive Immunology, 64; 58-67.

15. Sacks G, Yang Y, Gowen E, Smith S, Fay L, Chapman M (2012): Detailed analysis of peripheral blood natural killer cells in women with repeated IVF failure. Am J Reprod Immunol., 67: 434-442.

16. Beer AE, Kwak J, Ruiz J (1996): Immunophenotypic profiles of peripheral blood lymphocytes in women with recurrent pregnancy losses and in infertile women with multiple failed in vitro fertilization cycles. Am J Reprod Immunol., 35:376-382.

17. Michou VI, Kanavaros P, Athanassiou V, Chronis GB, Stabamas S, Tsilivakos V (2003): Fraction of the peripheral blood concentration of CD56 + /CD16-/CD3cells in total natural killer cells as an indication of fertility and infertility. Fertil Steril., 80(2):691-697.

18. Mehri G, Najmeh K, Ali K, Roshan N (2014): Increase of CD69, CD161 and CD94 on NK Cells in Women with Recurrent Spontaneous Abortion and in Vitro Fertilization Failure. Iran J Immunol., 11(2): 126-129.

19. Baczkowski $T$ and Kurzawa $R$ (2008): Immunophenotypic profiles of peripheral blood lymphocytes on the day of embryo transfer in women undergoing in vitro fertilization. Folia Histochemica et Cytobiologica, 45:73-2. 